\title{
A Proposed Framework for Improving Supply Chain Management using Block Chain
}

\author{
Atef Ghalwash, Shimaa Ouf, Marina Wassef \\ Faculty of Commerce and Business Administration, \\ Business Information System Department, \\ Helwan University, Egypt
}

\begin{abstract}
The greater usual way to supply chain has continually been a website that has been introduced on a server the association has to create or be introduced from an association (provider). The supply chain data is circumscribed here, thereforereducing the supplies of data, raising the danger aspects, inflexible system. The orders, updates, transitions, reaching details, and the details of clients, merchants, and makers of natural resources, constructors, and others have to be distributed, particular spotlight on the clarity altercation in medicine history. Electronics for health management these days are a progressing field seeing considerable jump in modern use of science and engineering to improve patient care. Medicine organizations serve huge residents, and nowadays have been seeing their supply chains progressively insecure by evil searching of pharmacy supply chain applying block chain technology. Applying block chain dispersed form decreases the data barring dangers and guarantees clarity and certification of medicine. Block chain technology can successfully make a supply in registering each single advantage during its flow on supply chain; provide in tracking orders, receipts, and bills. The disintegration of this data across the different stages of pharmaceutical supply chain varying from drawing out natural resources, manufacturing, to dispersion will start a more elastic and clear system.
\end{abstract}

In this paper, a proposed supply chain framework via block chain will be introduced. This proposed framework describes the particular elements of block chain that influence supply chain like scalability, accomplishment, consent structure, secrecy considerations, location proof, expense and safety. These traits would in sequence result into a system where data flows rapidly than usual circumscribed way ti supply chain management.

\section{Keywords}

Counterfeiting medicine, pharmaceutical supply chain, Block chain, Traceability, Smart contract, Distributed ledger, Transparent.

\section{INTRODUCTION}

Block chain is shortly gaining the interest of a big large type of industries: from money, health-care, utilities, and the authorities' area. The goal of the increasing interest: with a block chain, programs that worked most effective through a common agent. Nowadays, they could perform in a disperse method, without the need for a verification apparatus and earn the same performance with the exact quantity of dependability. This transformed into not any more transformation until the block chain became constructed. With the application of block chain uncertain networks appeared. That is reasonable as a result of the fact in networks that use block chain you can make transmissions and not using a need to count on various users. Block chain can allow transactions and payments to be used without any agent, which the absence of negotiators, transactions become more rapid among users. Besides, using cryptography inside the block chain secures that the records is relaxed[1].

Block chains are regarded as general (and lately private) ledgers containing negotiable information inside their disperse statistics systems, which form a strongly connected blocks. Unequal cryptography and disbursed consents methods are being expanded for achieving ledger stability, information stability, auditability, non-repudiation, and verification as a part of the constitutional security primitives. The assigned and dispersed nature of block chains makes them unchangeable in the experience that transactions can't be changed once they are formally identified by way of the peer of the network and recorded inside the block of the chain. On the same time, dependability and robustness are ingredient that constitute block chains as specially improve different problems which can be very dependent on shipment deterioration, human mistake, planned extortion, and others, correspondingly safety is one of the essential elements that should be addressed.

In the supply chain, all data changed happens to accomplish different shapes and must achieve different desires that generate more demanding control course and guarantee immutability and safe clarity between transactions and their data, without even this assurance most of the time. Such as, a wicked group participating in supply chain can maneuver invoice information and illegally change the values paid or received. So, it is essential to adopt system for immutability and to assure confidentiality of transactions in supply chain us cases. Block chain support a solution for the safety problems it supplies along the supply chain and assures integrity and clarity omission for drugs [2].

Besides, to fulfill the needs of shops, distributers need a huge amount of workers. All this assists in raising the opportunity of losing orders because of delaying in processing orders. To solve this problem, organizations have mechanized their methods, and this leads to a growth in the amount of organizations and suppliers inside the supply chain. That is, the growth in the quantity of digital dataand the extension of internet organizations means that the danger of attacking their databases. Hacker's change, erase or steal data. To supply safety for the data of organizations involved in the supply chain with the formation of the block chain, since the data is registered inside the block chain, it is hard to modify because this data is sent to everyone on the network [1].The medicine manufacturing supplies a healthcare service by supporting life-saving drugs.

But the big supply of fake medicine on the market aroused doubt among the public. Statistics present that this problem is specifically common in developing countries. There are many fake medicine cases registered in the world, such as, 
antimalarial medicine inherited in South Asia or the use of diethylene glycol toxin in making of fake paracetamol syrup. Medicine organizations and the government don't announce information about fake drugs because it may harm their sales. They also trust in the philosophy that "there is a need to do as much as possible in the darkness and there is no need to search for observable attention because of the fact that it can harm public trust in medicine."

The medicine supply chain is divided into three phases: 1) raw material extraction, 2) manufacturing, and 3) distribution. Deceitful events may lead to the growth of inferior medicine. Medicine organizations may fail to use suitable manufacturing technology, leading to the recording of products that don't meet quality standards. Supplying medicine to maneuver market prices was detected by the Food and Drug Administration in 2012, when fake copies of cancer medicine were introduced into US supply chain. People's confidence in medicine organizations and managers is harmed due to these activities. [13, 14, 15].

So, in this paper, we introduce a framework for developing the medicine supply chain. The block chain protects an unchangeable record of medicine each group holds and transactions the groups make among themselves.

\subsection{Definition of Pharmaceutical Supply Chain}

It is a channel through which medicineare shipped in the particularized volume, with the proper quality, in the proper place for clients, at the right time, and at an excellent price with the objects of the health system. Supply chain management constitutes the management of the progression path of goods and services, including the shipment and deposit of raw materials, supply chain management includes the form, preparation, execution, control and control of the exercises of goods and services adding value to the ultimate product. Supply chains, which were ultimately relied on business association networks, can support the ultimate product to customers through a series of actions, for example, eradication of raw resources, manufacturing to build the product, dispersion of the product to intermediaries (traders, merchants), and product customization to the public. These numerous activities are normally simulated as the transactions of the block chain network and the participants in the supply chain connect through this network [4].

Supply chain management in a medicine company assists in renovating the company to make excellent use of goods and property with clarity all enterprise technology, certainty of statistics, discounts in functional complexity, supporter selection, warehousing and dispersion [16].

\subsection{The Challenges of Pharmaceutical Supply Chain}

Pharmaceutical medicine has been and still are one of the most essential elements in the healthcare manufacturing used by doctors to diagnose, cure, avoid, and even treat diseases and rescue human lives. These medicines are designed to resist various kinds of diseases in the human body, varying from murdering or hesitant the spreading of microbes in the human body, fighting bacterial infections, to substituting definite chemicals that the human body can't produce enough quantity without external aid of pharmaceutical medicine. The factors needed to assure the influence of these pharmaceutical medicine are the two kinds of elements inside it, which are effective elements and excipients. Effective elements are contents in a medicine that produces a direct influence on the human body to cure symptoms while excipients are other chemically ineffective materials used to help effective elements in bringing the medicine into the human body.

According to the WHO (World Health Organization), fake medicine is defined as ones whose effective elements have been discharged with false elements, doesn't have any effective elements, or have incomplete quantity of effective elements. This leads the medicine to work variously than predicted, or not at all, making it harmful to sick people. Fake pharmaceutical medicine circulates the healthcare manufacturing universally and influences even developed countries, although it is most prominent in developing countries. The issue is related to how tight the country's legal controls are. In developed countries like the United States and Europe, WHO considers that less than one percent of pharmaceutical medicine sold, are fake. Nevertheless, in developing countries, experts say up to ten percent of pharmaceutical medicine sold are fake. Fake pharmaceutical medicine harsh a harsh cost on human lives. According to WHO estimations, fake medicine murder one million people yearly. For example, from the year 2008 is the case of contaminated heparin from China which resulted in circulating in 11 countries and lead to 81 deaths in the United States alone. Another example from the year 2012 in which Food and Drug Administration (FDA) found out fake versions of Avastin, a medicine used to cure cancer, doesn't include any effective elements and was circulating in the United States' medicine supply chain. More lately, there were illegal pharmaceutical elements in dietary supplements.

Fake medicine enters supply chains in the healthcare manufacturing through many methods. Firstly, universal healthcare supply chains mean that various elements that form a pharmaceutical medicine come from different parts of the world, that's why raising the complexity of the supply chain and making it more difficult for healthcare organizations to detect the origin of the medicine's elements. Effective and ineffective elements that form a medicine may come from suppliers located in various countries other than the one that disburses the medicine. Such as, most pharmaceutical medicine in the United States is formed from effective elements that come from other countries like China and India. Secondly, the present supply chain is opaque, where a process happening in the supply chain is invisible to all participants in the supply chain. This permits immoral participants in the supply chain to change, distort, or replace medicine as they travel the supply chain without the awareness of other participants. Like, there is a need to have a system to track the pharmaceutical medicine from industry to supplying, in the supply chain. Hence, to assure traceability in supply chain process, studied how to trace pharmaceutical medicine in supply chain system using lock chain technology. Connected testing to assure the influence and traceability of the recently designed supply chain system [4].

\subsection{Blockchain Technology}

The blockchain technology is a dispensed data structure that is copied and shared between the representatives of a network. A blockchain is built using cryptography. Each block is defined by its own cryptographic mess and each block indicates the mess of the former block. This builds a link between the blocks, making a blockchain.Therefore, users can communicate with a blockchain by using a coble of general and special keys. Miners in a blockchain need to conform on the transactions and the order in which they have happened. Alternatively, the personal copies of this blockchain can deviate producing a fork; miners then have various 
perspectives of how the transactions have happened, and it will be impossible to preserve a single block chain until the fork is not solved. To forward this a dispersed consensus mechanism is needed in every block chain network. Block chain's method to solve the fork issue is that each block chain node can link next block. Just a right unplanned number with SHA-256 should be found so you have number of zeros that the block chain predicts. Any node that can solve this puzzle has produced the so-called proof work and gets to form the chain's next block. Since a straightforward cryptographic mess function is included, any other node can quickly find out that the given reply meets the need.

Take care that a fork might still happen in the network, when two racing nodes mine blocks nearly concurrently. Like forks are commonly resolved unconsciously by the next block. With the performance of block chain, intelligent deals are involved to make transactions between various users more rapid and more effective. Nick Szabo recommended this idea in 1994 and identified an intelligent deal as "a computerized transaction protocol that executes the terms of a contract." Szabo implied that specifications of deals could be changed to code, thus decreasing the requirement for intermediaries in transactions between groups. In the block chain framework is an article that is saved on a black chain. Intelligent deals have an exclusive address in a block chain (i.e., they are in a block with a mess that defines it). We can generate an intelligent deal in a transaction by announcing the address on the block chain. It is executed freely and unconsciously in a recommended manner on every node in the network, according to the data included in the generated transaction [1].

Blockchain transactions are frequently confirmed, cleared, and saved by the network on all nodes in the digital blocks that conducted to previous blocks. Before a block chain can be accurate, it must assign to the previous block to be accepted and become accurate. This structure forever timestamps each transaction, which forbid anyone from changing the ledger [8].if one wanted to steal or change anything of value, he/ she would have to change the whole history of the cryptographically saved block chain. The concerted selfinterest of the block chain assures that this wouldn't occur and the block chain's security and dependency is assured [9].

Blockchainworks on peer-to-peer level, which depends on the network to confirm and accept transactions, and this has many benefits. It is dispersed, meaning it runs on computers spontaneously provided by users around the world and this means that there is no central database that is exposed to hacking. It is clear which means that anyone within the network can see it at any time.

It is encrypted meaning that it uses hard-burden encryption maintaining security. The main challenge with IoT devices today is their vulnerability to hacking and administration. Security challenges connected with IoT can be addressed as a result of the decentralized, independent and reliable abilities of blockchain [10]. Blockchain can check vulnerability of devices by making them run on blockchain platforms, by that, making the devices much more safe. Intelligent deals brutalize the transactions needed to progress, execute and implement a deal and its needs.But,these intelligent deals haven't been very influencing in terms of cost, time, and safety. Blockchain originally can provide an easy, cost-effective mechanism for the safety control and transaction of digital property with decreasedreliability on intermediaries and with the clarity of decentralized data. [11] But, the total widespread approval of intelligent deals is only predicted to occur after decades. This is because of the essential collaboration partnership and buyin of organizations. The tasks needed to design, confirm, achieve and apply the intelligent deals are enormous and it will take a long time to progress [12].

\subsection{Supply chain Before and After Blockchain Represent fig1, fig2 and table}

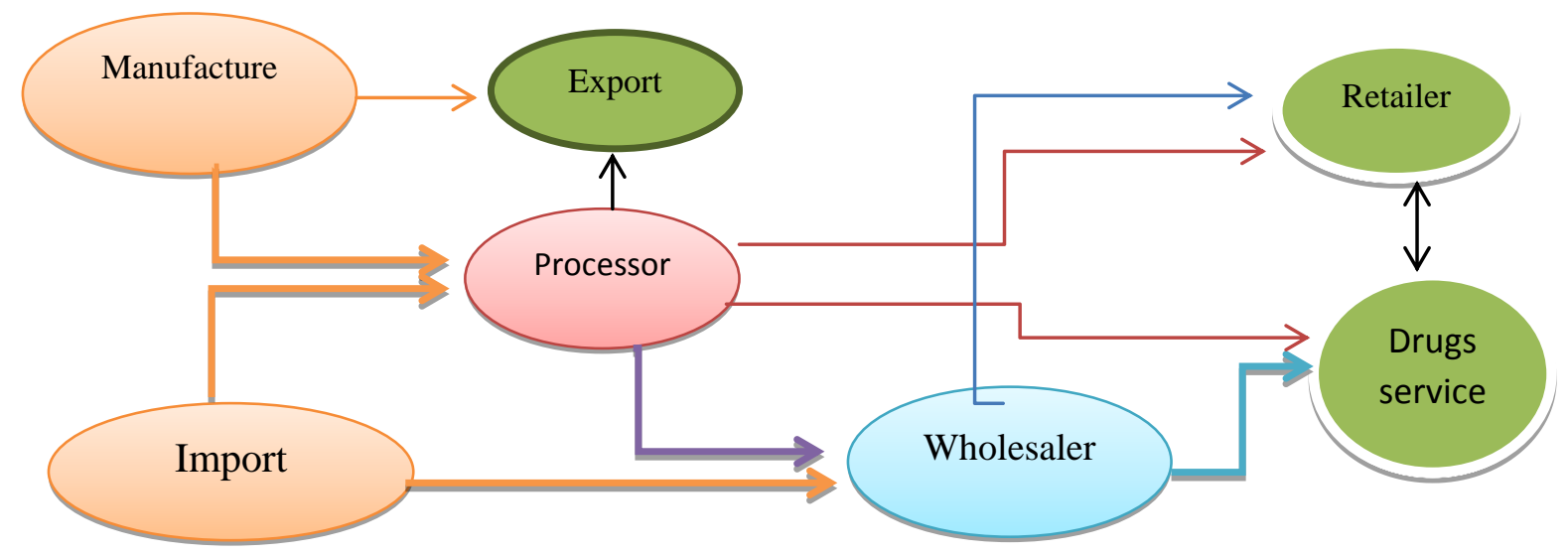

Fig1.Current Supply Chain[1] 


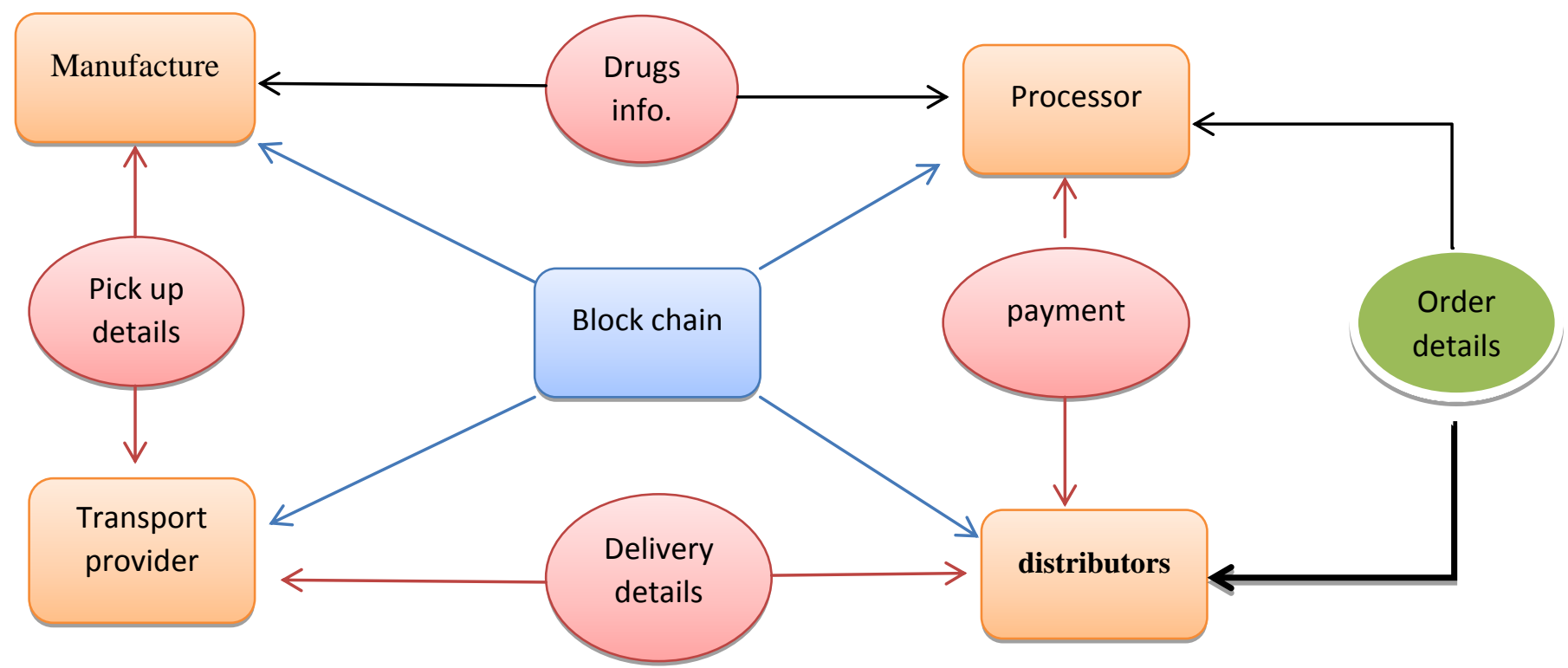

Fig.2. Supply Chain Via Blockchain [1]

Fig.1. Current supply chain model. This is a direct model from manufacturers and imports to tradersand medicine service. Fig .2. Through the formationof block chain, supplies chains are nowadays decentralized and all the transactions are put in blockchain. Each member of the supply chain can write their transactions on the blockchain. Nevertheless, members of the supply chain can only read those blocks of the blockchain that have a linearcontact with them.to logistics isn't a recent problem, in a multi-agent system is suggested to supply a resolution to the logistical problem. Also, another successful application of multi-agent systems is the problem of dispersed computing. Nevertheless, some of the offers that we find in the literature connect the advantages of block chain and multi agent systems. From a range of systems that merge block chain and multi-agent systems. Their work is worthy of mention. This work offers to use both technologies to raise safety and privacy in decentralized energy networks [1].

Table (4) Present the current limitation in the supply chain management and the impact of applying blockchain technology to improve this limitation

Table 1. supply chain actors, presentrestrains faced and block chain effect [4].

\begin{tabular}{|c|l|l|}
\hline Supply chain actor & Current limitations & After Appling Block chain \\
\hline Raw material/Producer & $\begin{array}{l}\text { Capability to justify in a universal and clear way } \\
\text { the origin and quality metrics of product. }\end{array}$ & $\begin{array}{l}\text { Profits from enlarged trust of keep record of } \\
\text { the production raw material and cost chain } \\
\text { from the raw material to the end customer. }\end{array}$ \\
\hline Manufacturer & $\begin{array}{l}\text { Bounded capacity to guide the medicine to the } \\
\text { ultimate destination. Bounded abilities of checking } \\
\text { quality measured from raw materials. }\end{array}$ & $\begin{array}{l}\text { Added cost from shared information system } \\
\text { with raw material suppliers and circulation } \\
\text { networks. }\end{array}$ \\
\hline Distributor & $\begin{array}{l}\text { Consumer tracking system with impoverished } \\
\text { combination prospects. Bounded recognition } \\
\text { capability and trust affairs. }\end{array}$ & $\begin{array}{l}\text { Capability to have evidence of residence and } \\
\text { conditions recognitions recorded in the } \\
\text { account book. }\end{array}$ \\
\hline Wholesaler & $\begin{array}{l}\text { Deficiency of trust and recognition of the product } \\
\text { course. }\end{array}$ & $\begin{array}{l}\text { Capability to check the origin of the } \\
\text { commodity and conversion / transportation } \\
\text { conditions. }\end{array}$ \\
\hline Retailer & $\begin{array}{l}\text { Deficiency of trust and recognition of the product } \\
\text { course. }\end{array}$ & $\begin{array}{l}\text { Deficiency of each personal medicine } \\
\text { between the end customer and the trader. } \\
\text { Capability to handle efficiently rebound of } \\
\text { faulty product. }\end{array}$ \\
\hline End user /Customer & $\begin{array}{l}\text { Deficiency of trust concerning the conformity of } \\
\text { the medicine with honor to origin, quality and } \\
\text { conformity of the medicine to the particularized } \\
\text { standards and origin. }\end{array}$ & $\begin{array}{l}\text { Complete and clear view on the medicine } \\
\text { origin and its entire journey from raw } \\
\text { material to ultimate, bought medicine. }\end{array}$ \\
\hline
\end{tabular}




\section{PROPOSED FRAMEWORK}

Supply chain management systems perform a crucial role in different activities of different industries. The main goal of supply chain management is to increase customer value and ensure sustainable competitive advantage. Supply chain management relies on each partner in the loop, starting from supplier and ending at the manufacturer and beyond. Accordingly, supply chain systems are expansive, complex, and require trust insurance. It is crucial also to transmit information smoothly between the partners in the supply chain system. In this regard, IoT technologies can help to improve the timely responses and information storage. On the other hand, to ensure the security and transparency of the supply chain transactions, blockchain technology is an appropriate choice, considering the efficiency and effectiveness requirements that are required for supply chain systems.

In order to provide a trust model for the integrated IoT-based supply chain with blockchain, our proposed trust model is shown in Figure 3. The conceptual model in Figure 3 depicts a blockchain supply chain based on the IoT and the suggested trust model. The key data providing coherence and traceability of the events within the depicted supply chain (including the key product data, sensor data, and data from some additional sources) should be logged in a way that prevents any possible tampering with the data. This can be provided by the deployed blockchain technology. The model we propose verifies all the logged information and reproduces the true observation of the entities within the supply chain, utilized sensors, and other sources of data, which is essential for establishing trust in the original information and ensuring that the blockchain-logged data will be considered trustworthy.

The proposed framework consists of four layers of shown in figure (3):

\section{A proposed framework for improving supply chain management using blockchain}

\section{Supply chain \\ layer}

\section{GovernmentSuppliersManufacturer Retailers Distributorscustomer}
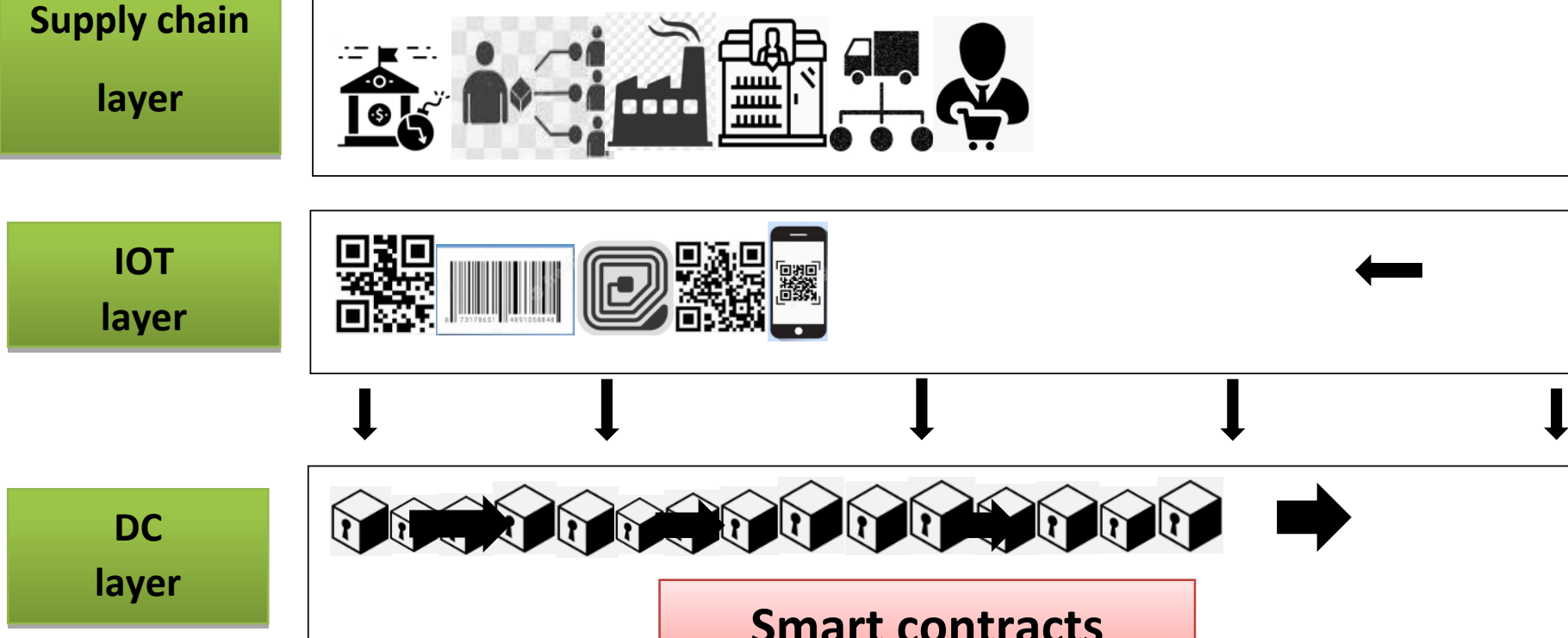

\section{Smart contracts}

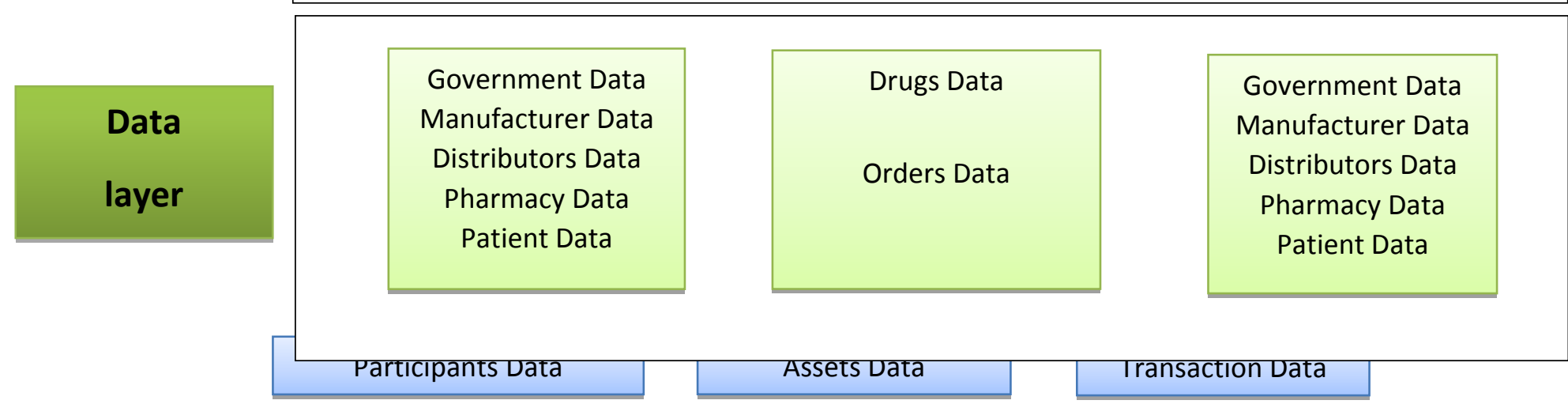

Figure 3.A Proposed Framework for Improving Supply Chain Management using Blockchain

The bottom layer is Data Layer, including three kinds of data:Participant's data, Asset's data and transaction data. Furthermore, all the enterprises keep a copy of data on supply chain including Government, manufacturer, DistributorsandPharmacy. With these data orinformation, smart contracts are used to execute quality control and improve the efficiency of supply chain.

The second layer is Contract Layer,only data sharing isnot enough. Data gathering in the layers above not onlyfacilitate 
data sharing but also aims to assist quality controland improve efficiency of supply chain. The first concernabout the data sharing may be the privacy issues. Privacyissues need to be considered for data sharing.Because competitive enterprises are operating on the same supplychain, some information needs to keep confidential for their own competitive advantages.Smart contracts also facilitate requirements of customerstransmit from retailers to manufacturers and then to suppliers. There are many functions that smart contracts can achievewith the data in blockchain. For example, with the retailers'transaction data, smart contracts analyze the ultimatecustomers' demands automatically and provide suggestionsabout purchasing and producing to manufacturers andsuppliers.

The third layer IOT layer, to monitor produce the distribution of drugs in real time. we created a model that allowed entities to trace products in a supply chain. The model was based on the hypothesis that it has to collect, save, and distribute information through the entire supply chain using a block chain andIoT systems. UsedRFID technology to move perishable products from the supplier to the retailer and consumer's perspectives. A key finding of their study was that RFID technology had the potential to benefit every party in a supply chain of perishable goods.

we using RFID technology to trace and drugs safety. Because the active distribution of data required the use of decentralized information servers, such servers used object names and discovery services in the framework. to addressing several challenges in the existing centralized system using RFID and block chains. A decentralized system was then developed to trace the movement of information in the supply chain.Although many trust models have been proposed for supply chains based on block chains and the IoT, a lightweight model is still required to guarantee secure and efficient management for supply chain transactions. Additionally, the proposed trust model aims to solve several trust issues in a decentralized approach where the nodes do not need to spend too much energy and waste computational power for performing block chain transactions.

The top layer is Business Layer,this layer includes various business activities in enterprises. Each enterprise on supply chain is able to control and manage the products qualities with the support of block chain and smart contracts. They also make decisions on purchasing and manufacturing activities based on the suggestions provided by the smart contracts.this layer constituted from The Government develops the specification of the medicinal product and registers the new medicinal product in the distributed register by means of the transaction of creation of the "Type of medicinal product" asset. In order to enable production, it also registers a "production License" and issues it to the registered participant-manufacturer, indicating a link to his account. If it revokes a license, a transaction marks the license as "invalid". There is also a need for a transaction to prolongate. 


\section{Participants}

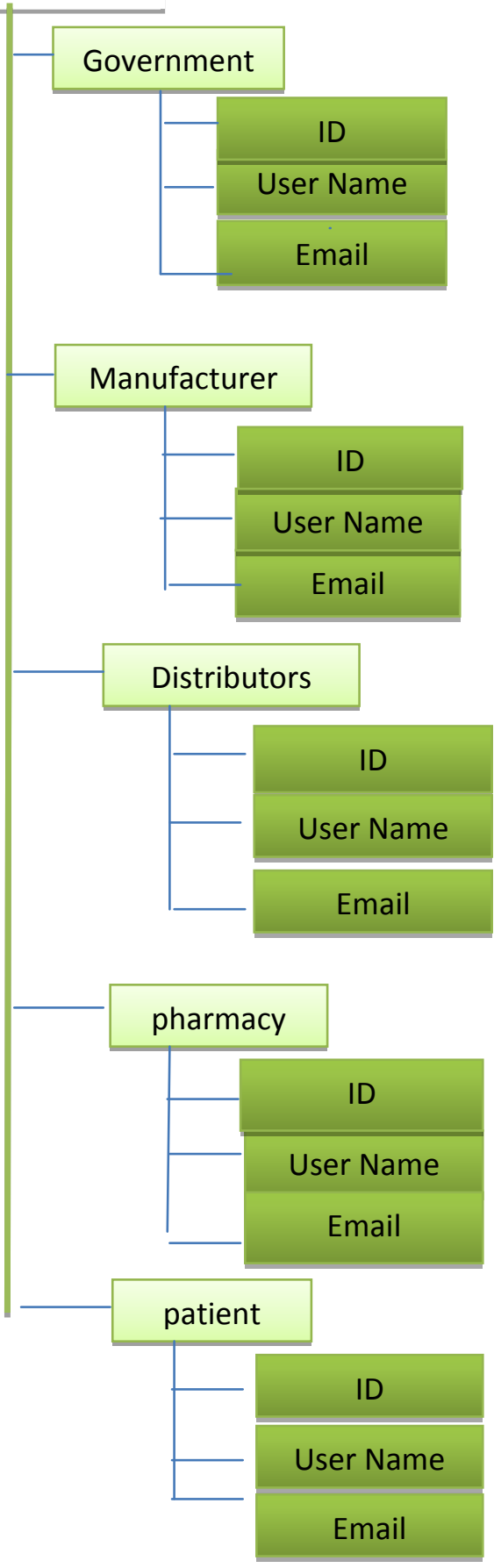

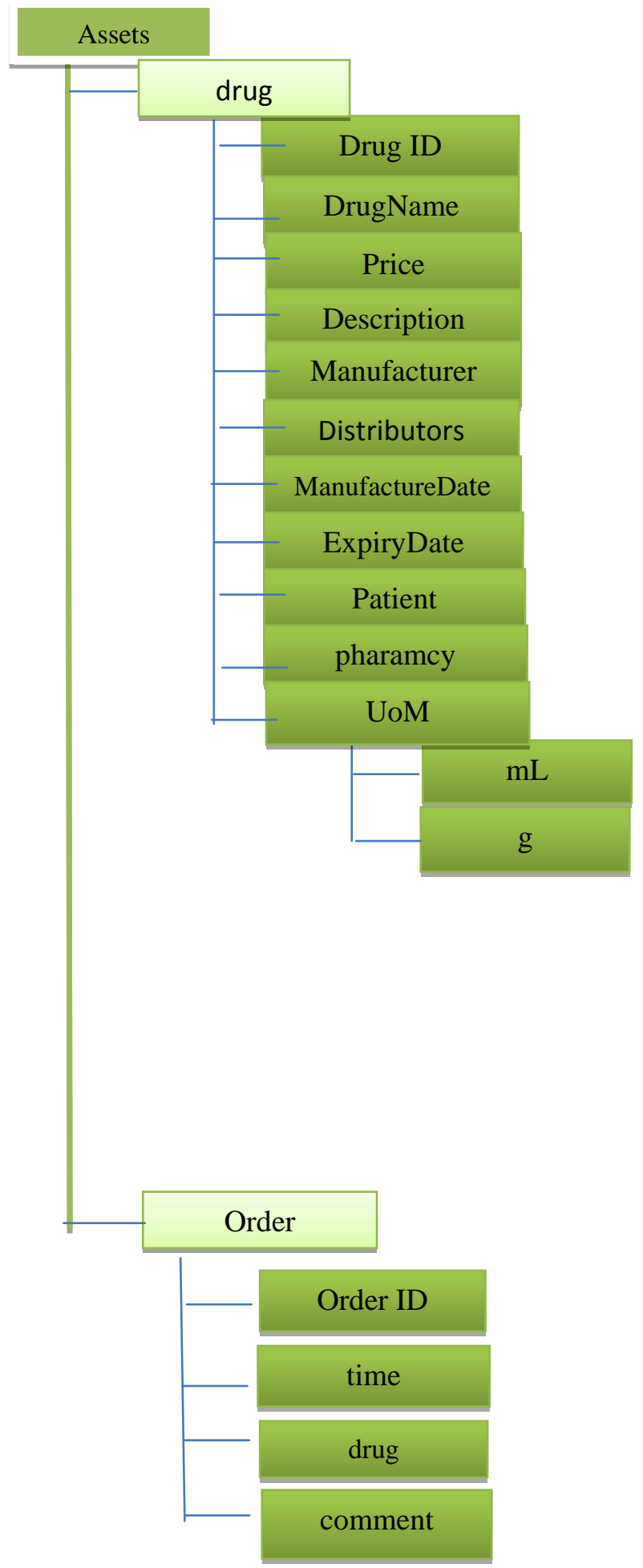

\section{Figure 4 Business Network for the Proposed system}

There are three main components for building a business network, i.e., participants, assets, and transaction. The proposed business network is shown in Figure 4. The participants in the proposed network are the Government, Manufacturer,Distributors,pharmacy, and patient. The assets include the drug, orders. Lastly, the transaction contains The Government: It is both the administrator and the developer of the network and it owns all registry nodes. The Government account has the ability to register the other members of the network and make transactions for the issuance of licenses for the production of drugs to manufacturers. It also registers new drugs in the information system, The Manufacturer: Produces goods and takes orders from the distributors. The manufacturer's account has the ability to register units of drugs in the system, as well as to create transactions on the transfer of ownership of a unit of drugs to thedistributors, The distributors:takes orders from the Pharmacy.The manufacturer's account has the ability to register units of drugs in the system, as well as to create transactions on the transfer of ownership of a unit of drugs to 
thePharmacy, The Pharmacy: Sells goods to citizens Pharmacy account has the ability to create a transaction for the transfer of ownership of drugs to the citizen. the account which has the right to buy a certain type of medication, The Citizen(patient): When buying prescription drugs. Thus, the end of the lifecycle of the drug unit resource in the system is a mark by the pharmacy on the sale of a certain unit in the virtual doctor's prescription, as well as a mark on the unit of the drug of the last owner - a Citizen or the Government.

Lastly, the end user receives the final drug followed by a submitted transaction (with appropriate tags included) and is able to check and verify its every aspect from the beginning of its supply chain journey until that moment.

\section{CONCLUSION}

The proposed Framework represent block chain based secure infrastructure for medical chain supply among valid participants. The mentioned framework can provide drug security as well as authenticity of manufacturer. The Current medical chain framework is working on third-party trust which is not very secure for the drug safety.

\section{REFERENCES}

[1] 1.Casado-Vara, R., Prieto, J., De la Prieta, F., \&Corchado, J. M. (2018). How blockchain improves the supply chain: Case study alimentary supply chain. Procedia computer science, 134, 393-398.

[2] Litke, A., Anagnostopoulos, D., \&Varvarigou, T. (2019). Blockchains for Supply Chain Management: Architectural Elements and Challenges Towards a Global Scale Deployment. Logistics, 3(1), 5.

[3] .Jamil, F., Hang, L., Kim, K., \& Kim, D. (2019). A novel medical blockchain model for drug supply chain integrity management in a smart hospital. Electronics, 8(5), 505

[4] Mohana, M., Ong, G., \& Ern, T. (2019). Implementation of Pharmaceutical Drug Traceability Using Blockchain Technology. Inti Journal, 2019(35).

[5] Alangot, B., \&Achuthan, K. (2017, August). Trace and track: Enhanced pharma supply chain infrastructure to prevent fraud. In International Conference on Ubiquitous Communications and Network Computing (pp. 189-195). Springer, Cham.

[6] Choi, J. B., Rogers, J., \& Jones, E. C. (2015, August). The impact of a shared pharmaceutical supply chain model on counterfeit drugs, diverted drugs, and drug shortages. In 2015 Portland International Conference on
Management of Engineering and Technology (PICMET) (pp. 1879-1889).

[7] Altunkan, S. M., Yasemin, A., Aykaç, İ. T., \&Akpinar, E. (2012, April). Turkish pharmaceuticals track \& trace system. In 2012 7th International Symposium on Health Informatics and Bioinformatics (pp. 24-30.

[8] Jochumsen, M. L., \& Chaudhuri, A. (2018, June). Blockchain's impact on supply chain of a pharmaceutical company. In EUROMA Conference 2018.

[9] Don Tapscott, A. T. (2017), "How will blockchain change organisations", MIT Sloan managment Review, Vol. 58, No.2., pp.10-13.

[10] Kshetri, N. (2017). Can Blockchain Strengthen the Internet of Things. IEEE Computer Society. Vol.19, No. 4, pp.68-72.

[11] Giancaspro, M. (2017), "Is a "Smart contract" really a smart idea? insights from a legal perspective", Computer Law \& Security Review, Vol. 33, No. 6, pp. 825-835.

[12] Iansiti, M. (2017), "It Will Take Years to transform business, but the journy begins now", Harvard Business Review, Vol. 95, No. 1, p.118-128.

[13] Bryatov, S. R., \&Borodinov, A. (2019, May). Blockchain technology in the pharmaceutical supply chain: Researching a business model based on Hyperledger Fabric. In Proceedings of the International Conference on Information Technology and Nanotechnology (ITNT), Samara, Russia (pp. 21-24).

[14] Bocek, T., Rodrigues, B. B., Strasser, T., \& Stiller, B. (2017, May). Blockchains everywhere-a use-case of blockchains in the pharma supply-chain. In 2017 IFIP/IEEE symposium on integrated network and service management (IM) (pp. 772-777). IEEE.

[15] Tönnissen, S., \&Teuteberg, F. (2020). Analysing the impact of blockchain-technology for operations and supply chain management: An explanatory model drawn from multiple case studies. International Journal of Information Management, 52, 101953.

[16] Ahmadi, V., Benjelloun, S., El Kik, M., Sharma, T., Chi, H., \& Zhou, W. (2020, February). Drug Governance: IoT-based blockchain implementation in the pharmaceutical supply chain. In 2020 Sixth International Conference on Mobile And Secure Services (MobiSecServ) (pp. 1-8). IEEE. 